\title{
Capsule Commentary on He et al., How Do Women View Risk-Based Mammography Screening? A Qualitative Study
}

\author{
Lydia E. Pace, MD, MPH \\ Division of Women's Health, Brigham and Women's Hospital, Boston, MA, USA.
}

$\mathrm{J}$ Gen Intern Med 33(11): 1957

DOI: $10.1007 / \mathrm{s} 11606-018-4645-\mathrm{x}$

(c) Society of General Internal Medicine 2018

$\mathrm{T}$ his qualitative study investigates women's attitudes regarding the concept of risk-based breast cancer screening, or the process of tailoring screening recommendations based on a woman's breast cancer risk. ${ }^{1}$ The authors conducted four focus groups with 29 women at which they presented women with a description of the risk-based screening paradigm and women discussed their impressions.

Women expressed mixed feelings about a risk-based approach. Some women expressed confusion and skepticism about "traditional" screening strategies, including questioning the motivations of providers and the health care system in the trend towards reduced screening. Although some women felt that a risk-based approach made sense, some were concerned about the possibility of under-screening and missed cancers, and some questioned the accuracy of risk models to predict an individual's risk.

National screening guidelines have increasingly recommended an individualized approach to breast cancer screening. The increasing age thresholds for screening initiation recommended by major guidelines ${ }^{2,3}$ reflect the reality that older women are at higher risk of breast cancer, and higher-risk women face a more favorable ratio of benefits to harms from screening. However, how to operationalize risk-based screening in primary care settings remains unclear. ${ }^{4}$ In addition to uncertainty about appropriate risk thresholds for screening strategies, and the limitations of existing risk models, a riskbased approach requires more patient and provider education, integration of risk assessment tools into practice, and more visit time.

This article introduces some of the questions that many patients will have about this approach, and highlights the need for other areas of study. Understanding the perspectives of women with less education, and women of color, and developing appropriate educational tools will be critical, along with examining their implementation. Importantly, studies have suggested that high-quality decision aids can effectively help patients incorporate considerations of false positive results and overdiagnosis into their screening decisions. ${ }^{5}$ The mistrust communicated by some patients in this study will require concerted efforts to address. Ultimately, however, risk-based screening represents an attempt to optimize patients' experiences and outcomes. This is a goal about which patients and providers should agree.

Corresponding Author: Lydia E. Pace, MD, MPH; Division of Women's Health, Brigham and Women's Hospital, Boston, MA, USA (e-mail: lpace@bwh.harvard.edu).

\section{Compliance with Ethical Standards:}

Conflict of Interest: The author declares that she does not have a conflict of interest.

\section{REFERENCES}

1. He X, Schifferdecker KE, Ozanne EM, Tosteson ANA, Woloshin S, Schwartz LM. How do women view risk-based mammography screening? A qualitative study. J Gen Intern Med. 2018. DOI: https://doi.org/10. 1007/s11606-018-4601-9

2. Haas JS. The complexity of achieving the promise of precision breast cancer screening. J Natl Cancer Inst. 2017;109(5). https://doi.org/10. 1093/jnci/djw301.

3. Final Recommendation Statement: Breast Cancer: Screening - US Preventive Services Task Force. https://www.uspreventiveservicestaskforce.org/ Page/Document/RecommendationStatementFinal/breast-cancer-screening1. Accessed 27 July 2018.

4. Oeffinger KC, Fontham ET, Etzioni R, et al. Breast cancer screening for women at average risk: 2015 guideline update from the American Cancer Society. JAMA. 2015;314(15):1599-1614.

5. Hersch J, Barratt A, Jansen J, Irwig L, McGeechan $\mathbf{K}$, Jacklyn $\mathbf{G}$ Thornton H, Dhillon H, Houssami N, McCaffery K. Use of a decision aid including information on overdetection to support informed choice about breast cancer screening: a randomised controlled trial. Lancet. 2015; 385: $1642-52$.

Published online September 10, 2018 